\title{
Factors Associated with Reproductive Behavior of Low Income Mothers in Kiandutu Slum in Thika Municipality, Kenya
}

\author{
Jane N. Kieru ${ }^{1}$, Lucy W. Ngige ${ }^{1} \&$ Alice N. Ondigi ${ }^{2}$ \\ ${ }^{1}$ Department of Community Resource Management and Extension, Kenyatta University, Nairobi, Kenya \\ ${ }^{2}$ School of Hospitality and Tourism, Kenyatta University, Nairobi, Kenya \\ Correspondence: Alice N. Ondigi, School of Hospitality and Tourism, Kenyatta University, Nairobi, Kenya. Tel: \\ 25-471-196-6258. E-mail: ondigialice@yahoo.com
}

Received: January 15, 2012 Accepted: February 14, 2012 Online Published: August 18, 2015

doi:10.5539/ass.v11n24p350

URL: http://dx.doi.org/10.5539/ass.v11n24p350

\begin{abstract}
The purpose of this study was to investigate maternal factors associated with reproductive behavior of low income mothers in Kiandutu slum in Thika Municipality, Kenya. The family resource management model and the safe motherhood theoretical framework guided the study. A survey of 120 randomly selected mothers was conducted using simple random sampling. Data was collected using both qualitative and quantitative methods. Results showed that the level of education $(p=0.000)$, occupation $(p=0.037)$, income levels $(p=0.040)$, religious affiliation $(p=0.007)$ and attitude towards contraception $(p=0.000)$ had significant relationship with mothers' reproductive behavior. However, age, marital status, ethnicity contraceptive knowledge and use were not significantly related to reproductive behavior. Implications for fertility, family size, family planning, and involvement of males in reproductive health are included in the discussion. The study recommends that reproductive and sexual health education be made available to women and girls of childbearing age. This will help to empower them to take control of their own fertility.
\end{abstract}

Keywords: reproductive behavior, fertility, family size, family planning

\section{Introduction}

The purpose of this study was to investigate maternal factors associated with reproductive behavior of low income mothers in Kiandutu slum of Thika Municipality. The study was based on Deacon and Firebaugh (1988) family resource management model and the safe motherhood model by McCarthy and Main (1994). In this research, the focus was on the relationship between maternal inputs or contextual determinants and throughputs or intermediate determinants, and the outputs of reproductive behavior. Contextual determinants were defined as maternal factors such as age, education, occupation, income, cultural and religious beliefs which influence directly or indirectly their reproductive behavior. Intermediate determinants were throughputs or transformation factors such as maternal decision making patterns, knowledge, attitudes and use of contraceptives for the management of fertility. Proximate determinants were the outputs which were characterized by fertility and reproductive behavior.

\subsection{Objectives}

The study was guided by the following objectives:

1. To analyse the socio-demographic characteristics of low income mothers.

2. To assess knowledge, attitude and use of contraceptives of low income mothers.

3. To investigate decision making patterns on contraceptives by low income mothers.

\subsection{Null Hypotheses}

The study sought to test the following hypotheses:

1. There was no relationship between maternal socio-demographic characteristics and reproductive behavior.

2. There was no relationship between maternal knowledge, attitude and use of contraceptives and reproductive behavior.

3. There was no relationship between maternal decision making power and reproductive behavior. 


\section{Review of Related Literature}

Human fertility is a complex process responsible for the maintenance of human society (Ngige \& Wilson, 2006). African people have long valued fertility and therefore many couples have large families. In the past, many African families measured their riches by the number of healthy children they had. According to Centre for Minority Rights and Development [CEMIRIDE] (2007), the Sub-Saharan Africa has the lowest rate of contraceptive use in the world, making it to have the highest unmet need for contraceptives. This is contributed by difficulties in getting contraceptives supplies, lack of adequate family planning clinics, low social economic levels and the high value many cultures place on large family size.

This high fertility and difficulties in contraceptive supplies impacts greatly on low income mothers who are characterized by limited education and training skills, chronic low incomes, recurring health problems and they are either unemployed, underemployed or have unreliable employment which provides low incomes (Ngige \& Wilson, 2006). Hence they are unable to purchase good quality food leading to reduced nutrient intake and therefore they are vulnerable to malnutrition. These mothers lack access to good health care which leads to poor health which in turn affect productivity on the job and compound the already low income by being absent from work. Children also lack access to education hence facilitating the vicious cycle of poverty from one generation to another (Ngige \& Wilson, 2006).

According to Kenya housing and population census 2009, it indicated a larger proportion of households with more than six members of the family were categorized as poor. Likewise looking at the Kenya economic survey, it was observed that poverty in Kenya has been persistent and on the increase in the last 20 years. For example in 1992 poverty levels were at $46.4 \%$ and have steadily increased to $52.3 \%$ in 2007 (Kenya, 2007). Despite the fact that poverty trends are still on the rise, there has been no desire among low income mothers to limit the number of children they have even when the urban and rural economic prospects seems so grave. Hence there was a need for more research to investigate aspects of reproductive behavior of low income mothers where crucial gaps still exist as they seem to have a high fertility level despite the economic constraints they go through. Therefore given the foregoing scenario in Kenya there was need to examine maternal factors associated with reproductive behavior of low income mothers.

\section{Methodology}

The research proposal was reviewed by Kenyatta University and the Ministry of Education, Science and Technology, and a letter of research authorization with a research permit granted. Participation in the study was purely on voluntary basis, and respondents were fully informed of the research objectives and methods. Informed consent was sought from the mothers before any information was gathered. Confidentiality of the participants' identities were assured and kept by use of identification codes throughout the study and in all subsequent reports. Mothers who were willing and able to participate in the study were scheduled for a face-to-face interview in their homes conducted by trained researchers. According to Ary, Jacon and Razeviah (1972) 10-20 per cent of the sample representation is adequate. The total number of households in Kiandutu slum according to the Central Bureau of Statistics was approximately 1587. The sample size was made up of 10 per cent of the population, which was approximately 150 households. The slum has one cluster and the houses are systematically built though not physically numbered.

The researcher used systematic sampling method where the first household was picked randomly and the remaining households were picked at pre-determined interval of 10. Therefore after picking the first household randomly, every $10^{\text {th }}$ household was considered as an element under study. However 16 households were dens for illegal brew (changaa) and due to insecurity reasons, they were not sampled, hence 134 households formed the sample size. Out of these 134 interviews, 14 of them were incomplete and were not considered in the analysis as the respondents refused to answer some of the important questions guiding the study. Hence the final population of the sample under study consisted of 120 randomly selected mothers living in Kiandutu Slum in Thika Municipality. An interview-questionnaire was developed with three parts: the first part elicited information on socio-demographic characteristics of the informants. The second part contained information on knowledge, attitudes and use of contraceptives and the last part dealt with mothers' decision making patterns on issues pertaining to reproduction and fertility management. Data were collected in home interviews scheduled by appointment that lasted about two hours. All interviews were conducted in the national language, Kiswahili and later translated into English. 


\section{Results}

\subsection{Sample Socio-demographic Characteristics}

The mothers ranged in age between 15 and 44 years, $77.5 \%$ were married, $10 \%$ single, and $12.5 \%$ were either separated or divorced. In terms of the highest level of formal education, $85 \%$ had completed primary school and $15 \%$ had completed secondary education. None of the respondents had attained post-secondary or tertiary level of education. The religious affiliations were Christian (70\%) and Muslims (5\%) and others (25\%). The occupations of the respondents in ranked order were business women in micro and small enterprises (65.5\%), unskilled or casual laborers $(25 \%)$ and housewives (12.5\%). In terms of daily income, about two-thirds earned less than a dollar a day (Kenya Shillings 78 per day or 2340 per month). This is below the absolute poverty line in Kenya for urban areas whose cut-off was 2648 Shilling per month (Kenya, 2007). The ethnic groupings included Kikuyu (55\%), Kamba (30\%) Luo, Borana and others (15\%).

\subsection{Knowledge, Attitudes and Use of Contraceptives}

The results indicated that $95 \%$ of the respondents had knowledge of contraceptives where pills and injectables were widely known with the least known being tubal ligation and norplant. This is supported by Thumbi (2004) who found similar findings. Such knowledge of contraceptives was mainly obtained from the health clinics followed by through friends. Likewise more than three quarters of the respondents $(77.5 \%)$ indicated that they were using some form of contraception and the widely used ones were the pills and injectables which were the mostly known. The main reason for the non-use of contraceptives was indicated as side effects associated with them. In addition, the respondents were also generally found to have positive attitudes toward contraceptives.

\subsection{Maternal Decision Making Power on Contraception}

The self-reports indicated that $70 \%$ of the mothers made decisions on whether or not to use contraceptives and which type to use. However $85 \%$ of the husbands decided when to have sex and the number of children the couple should have. Both partners had a say on when to have children. A critical look at the results revealed that even though the women had knowledge about contraceptives, this gain was undermined by the fact that it was the husband who decided on the family size. This finding is supported by other researchers who asserted that women in most African cultures have limited power over their sexual and reproductive lives (Ascardi, 1990).

\subsection{Reproductive Behavior}

Reproductive behavior was measured by three indices namely: total number of children born per woman, age at first birth and age at first marriage. The number of children born per woman ranged from 3 to 5 with an average of 4. The age of the mothers at first birth indicted that slightly more than half (52.6\%) had their first child at the age of 17 years or more while age at first marriage showed that majority of them $(56.5 \%)$ got married at the age of between 18 to 20 years. After computation it was shown that a large proportion of the respondents $(59.8 \%)$ had moderate reproductive behaviour.

\subsection{Hypotheses Testing}

\subsubsection{There Was No Relationship between Maternal Factors and Reproductive Behavior}

Analytical results for this hypothesis indicated that four contextual determinants namely: level of education $(p=0.000)$, occupation $(p=0.037)$, income levels $(p=0.040)$ and religious affiliation $(p=0.007)$ were significantly related to reproductive behavior of low income mothers. However, marital status and ethnicity had no significant relationship with reproductive behavior (Table 1).

Table 1. Relationship between maternal characteristics and reproductive behavior

\begin{tabular}{cccc}
\hline Maternal Variable & Value $\left(\mathrm{x}^{2}\right)$ & $\mathrm{df}$ & Significance \\
\hline Age & 6.551 & 4 & 0.162 \\
Education level & 30.407 & 2 & $0.000^{* *}$ \\
Marital status & 4.629 & 6 & 0.592 \\
Occupation & 10.212 & 4 & $0.037^{* *}$ \\
Income level & 10.025 & 4 & $0.040^{* *}$ \\
Ethnicity & 5.805 & 4 & 0.214 \\
Religion affiliation & 17.634 & 6 & $0.007^{* *}$ \\
\hline
\end{tabular}

\footnotetext{
$* *$ Significant at $\mathrm{p} \leq 0.05$
} 
Results indicated that mothers' level of education $(p=0.000)$, occupation $(p=0.037)$, level of income $(p=0.040)$ and religious affiliation $(p=0.002)$ showed a significant relationship with reproductive behavior. Thus the null hypothesis was retained. However, marital status and ethnicity had no significant relationship with reproductive behavior.

4.5.2 There Was No Relationship between Contraceptive Knowledge, Use and Attitude and Reproductive Behaviour

Attitude towards contraceptives was found to be significantly related to reproductive behaviour $(\mathrm{p}=0.000)$. Knowledge and use of contraceptives were not found to be significantly related to reproductive behaviour. (Table 2) However knowledge of contraceptives was found to be significantly related to marital status $(\mathrm{p}=0.039)$ and income levels $(\mathrm{p}=0.003)$. In analyzing the extent of the use of contraceptives, it was noted that factors such as age $(\mathrm{p}=0.01)$, income levels $(\mathrm{p}=0.04)$ and occupation $(\mathrm{p}=0.002)$ were significant. Also attitude towards contraceptives was found to be significantly related to all maternal socio-demographic characteristics under study; age $(p=0.000)$, level of education $(p=0.000)$, marital status $(p=0.001)$, occupation $(p=0.000)$, income $(\mathrm{p}=0.009)$, religious affiliation $(\mathrm{p}=0.000)$, ethnicity $(\mathrm{p}=0.000)$. In turn attitude towards contraceptives was found to influence reproductive behavior of low income mothers. However for the non-users of contraceptives, the results showed that there were misconceptions that resulted in negative attitudes. For example, it was reported that the use of contraceptives either made women "promiscuous" or reduced their libido (sexual urge).

Table 2. Relationship between contraceptive knowledge, use and attitude and reproductive behaviour

\begin{tabular}{cccc}
\hline Variable & Value $\left(\mathrm{x}^{2}\right)$ & df & Significance \\
\hline Knowledge of contraceptive & 1.994 & 2 & 0.369 \\
Use of contraceptive & 1.119 & 2 & 0.572 \\
Attitude towards contraceptives & 46.010 & 16 & $0.000^{* *}$ \\
\hline
\end{tabular}

**significant at $\mathrm{p}=0.05$

The results of chi-square test in Table 4.40 shows that attitude towards contraceptives had a significant relationship $(\mathrm{p}=0.000)$ with reproductive behavior hence it influences reproductive behavior of low income mothers. Knowledge and use of contraceptives were found not to have an influence on reproductive behavior of low income mothers. Therefore the null hypothesis was rejected.

4.5.3 There Was No Relationship between Decision Making Patterns on Contraceptive and Reproductive Behaviour

The findings indicated that none of the maternal decision making patterns were significantly related to reproductive behaviour (Table 3 ).

Table 3. Relationship between decision making patterns on contraceptives and reproductive behaviour

\begin{tabular}{cccc}
\hline Decision making variables & Value & df & Significance \\
\hline Number of children to have & 7.929 & 6 & 0.243 \\
Whether to use contraceptives & 4.713 & 4 & 0.318 \\
Which contraceptives to use & 1.013 & 2 & 0.603 \\
Where to obtain the contraceptives & 1.013 & 2 & 0.603 \\
Who should obtain the contraceptives & 1.013 & 2 & 0.603 \\
When to have a child & 12.544 & 6 & 0.051 \\
When to have sexual intercourse & 3.028 & 4 & 0.553 \\
Who should use the contraceptive & 2.959 & 4 & 0.565 \\
\hline
\end{tabular}

Results showed that none of the decision making factors had significant relationships with reproductive behaviour. Therefore the null hypothesis was retained. 


\section{Discussion}

\subsection{Maternal Education and Reproductive Behavior}

Level of education was found to influence fertility since contraceptive prevalence increased dramatically with level of education. This is supported by other researches that have found extended education is related to postponement of marriage hence decreasing the child bearing period (Kenya, 2002). Education influences fertility as reported in the last two Kenya demographic and health surveys (Kenya, 2003, 2009) where contraceptive prevalence increased with the level of education. The report further asserted that $60 \%$ of married women at least with secondary education used contraceptives compared to $40 \%$ with primary education, and $14 \%$ who had never attended school giving clear-cut differences between women with little or no education and women with secondary level of education and higher. This finding was also supported by Kimani (2005) who reported that women with higher education had lower fertility rate than those with low or no education at all. Similarly, Bongaarts (2009) asserted that contraceptive prevalence decreased significantly among women with no education and those with no children, but increased among their more educated counterparts. He further posited that contraceptive prevalence was below $15 \%$ among the poorest and least educated women who lived in slum settlements in Kenya. Education also determines the type of occupation one was engaged in which in turn determined the level of income (Kenya, 2002). On marital status, married women had higher contraceptive prevalence rate than single women (Kenya, 2009).

\subsection{Maternal Age at Marriage and at First Birth}

Age at first marriage and first birth have been cited as factors influencing reproductive period in that recent researches have showed that girls entered into sexual union at an early age of 15 years which increased their fertility (Kenya, 2009). Girls enter into early marriages in anticipation of a better life hence prolonging their reproductive period. Previous research showed that knowledge of contraceptives is widespread (96\%) and this coupled with attitude towards contraceptives affects the use of contraceptives (Kenya, 2003, 2009). However a national survey revealed that 24 per cent of Kenyan women who would like to either space or limit births are not using a method of contraceptive reflecting a high unmet need (Kenya, 2009).

\subsection{Fertility, Contraceptives and Poverty}

The poorest in the society have the highest wanted and unwanted fertility rates and are the least able to access information and services on contraceptives Bongaarts, Askew, Ezeh \& Townsend (2009) reported that fertility of the Kenyan women living in the poorest households was more than two and half times (7.6) the total fertility rate of women in the richest households (3.1). Although the overall poverty incidence declined from $56 \%$ in 2000 to about $47 \%$ in 2006 , the poverty headcount was higher in women in both rural $(50 \%)$ and urban $(46 \%)$ areas (Kenya, 2007). A national survey showed that more than half of the Kenyan population live in absolute poverty with the likelihood that it will rise to $66 \%$ by 2015 if current issues are not addressed such as increasing inequality in the distribution of income and wealth (Centre for Minority Rights and Development, 2007).

An assessment of contraceptive usage by marital status indicated that married women had a higher contraceptive usage, which peaked among women within the age group of 30-34 years when the ideal family size had been attained. However it was lowest for women at the age of 15-19 years (Kenya, 2009). It has also been observed that over the years, the total fertility rate has been dropping from 8.1 births per woman between 1970 and the 1990s, to 4.9 in 2000-2002 period, and then declined to 4.6 in 2006-2008 (Kenya, 2009). This drop in fertility could be due to the fact that contraceptive use has increased considerably by married women from $39 \%$ in 2003 to $46 \%$ in 2009 . The total fertility rate in Kenyan urban areas is 2.9 births compared to 5.2 births in the rural areas (Kenya, 2009).

\subsection{Fertility by Age at First Marriage and Age at First Birth}

The median age at first birth in Kenya is 20 years (Kenya, 2009) and this is becoming an important indicator of fertility irrespective of the marital status. More than half of Kenyan women were married by their $20^{\text {th }}$ birthday (Kenya, 2009). When women enter child bearing at an early age their reproductive period is lengthened and fertility is high. It also asserts that median age at first marriage is increasing over time from 19.2 years in 1998 to 19.8 in 2003 and it is projected to increase to 20 years and thereby decrease the reproductive period of a woman hence implying fewer children.

\subsection{Knowledge, Attitudes and Use of Contraceptives}

According to the Kenya health and demographic survey (2009), contraceptive knowledge is almost universal with $96 \%$ of women aged $15-49$ years and $98 \%$ of men aged 15-54 years knew at least one modern method of contraceptives. The mostly commonly known methods are the male condom (91\%), pill (90\%) and injectables 
(89\%). A woman's knowledge of the source of contraceptives affects her use which is also affected by the attitude towards the contraceptives and the level of motivation to use them (Ross \& Winfrey, 2001). Modern methods are commonly used (39\%) than traditional methods $(6 \%)$ and this has fuelled an increase in the overall contraceptive prevalence rate (46\%) in Kenya. Of the modern methods, injectables are the most commonly used while periodic abstinence as the most popular traditional method (Kenya, 2009). The survey further reported that fertility preferences are closely related to the number of living children a woman has so that as the number of living children increases, the desire to have another child decreases and vice versa. For instance, $84 \%$ of married women with at least 5 children wanted no more children or were sterilized, in contrast to only 3 percent of women with no children. The national survey showed that more urban women (53\%) used contraceptives compared to their rural counterparts (43\%) (Kenya, 2009).

\subsection{Maternal Decision Making Patterns and Reproductive Behavior}

The results showed that the mother's decision making variables had no significant relationship with reproductive behavior hence the hypothesis was supported. This concurs with Ascardi et al. (1990) who reported that in some settings fertility decision making is beyond the control of an individual woman. Bolaji 1997 further asserted that reproductive behavior was controlled by people outside the family who did not recognize that making decisions on fertility should be left to the couple who are best placed to assess the costs and benefits of the choices made. Deutscher Entwicklungsdienst (2004) reported that the subordinate status of women also implied lack of control over their sexual relations which was worsened by their economic dependence on men. This perspective was supported by Zeba, Casterline \& Haque, 2001) who pointed out that contraceptive use and fertility prevalence were affected by decisions made within the family and in some cases it was controlled by people outside the family who did not recognize that decisions pertaining to fertility should be made by couples after weighing the costs and benefits of their choices.

\section{Conclusions and Recommendations}

This study has shown that maternal characteristics such as mother's level of education; occupation; level of income, religious affiliation and attitudes toward contraceptives were significantly related to reproductive behavior of low income mothers. The study therefore recommends that reproductive and sexual health education be made available to women and girls of childbearing age. This will help to empower them to take control of their own fertility. Low income mothers should also be assisted to come up with sustainable income generating projects to be able to provide for the family basic needs and break the vicious cycle of poverty.

Religious leaders should also address the issue of reproduction to their respective followers with emphasize on the plight of children. Men should be sensitized not only to allow their partners to make decisions on contraceptives, but also to give some room for their women to decide on matters dealing with sexuality and the number of children a couple should have. There should be co-operation between men and women when it comes to making decisions related to reproduction. Finally on attitude towards contraceptive, the findings showed that there were misconceptions that resulted in negative attitudes. These misconceptions and side effects associated with contraceptive use need to be addressed by health workers and family planning programme designers and implementers.

\section{References}

Ary, D., Jacob, L., \& Razeviah, A. (1972). Introduction to Research in Education. Holt Reinhart and Winson: New York.

Bongaarts, J., Askew, I., Ezeh, A., \& Townsend, J. (2009). Kenya Fertility Transition: Trends, Determination and Implication for Policy and Programs. Nairobi: Kenya. National Council for Population and Development.

Centre for Minority Rights and Development [CEMIRIDE]. (2007). Reproductive Health and Rights Alliance Committee on Economic, Social and Cultural Rights. Mazingira Institute, Nairobi Kenya..

Deutscher Entwicklungsdienst [DED]. (2004). Reproductive Health and HIV/AIDS in Kenya. Working Concept. Nairobi: Kenya .

Kenya. (2002). Analytical report of fertility and nuptiality. Nairobi: Kenya Central Bureau of Statistics.

Kenya. (2003). Demographic and Health Survey 2003. Nairobi: Central Bureau of Statistics.

Kenya. (2007). Analytical report on poverty. Nairobi: Kenya: Ministry of Finance and Planning.

Kenya. (2009). Demographic and Health Survey 2008-2009. Nairobi: Kenya National Bureau of Statistics.

Kimani, M. (2005). Fertility Change in Kenya from 1998-2003: The Role of Socio-economic change and 
Proximate Factors. Working Paper No. 1. Nairobi: Kenya. National Council for Population and Development.

Ngige, L. W., \& Wilson, S. M. (2006). Families in Sub-Sahara Africa. In B. B. Ingoldsby, \& S. D. Smith (Eds.), Families in global and multicultural perspective (pp. 247-273). Thousand Oaks, CA: Sage.

Ross, J. A., \& Winfrey, L.W. (2001). Contraceptive use, intention to use and unmet need. International family planning perspectives, 27(1), 20-21.

Thumbi, P. W. (2004). Reproductive Health and reproductive rights. Kenya country report. National Council for Population Development (NCPD).

Zeba, A. S., Casterline, J. B., \& Haque, M. U. (2001). Obstacles to contraceptive use. International studies in family Planning, 32(2), 98-99.

\section{Copyrights}

Copyright for this article is retained by the author(s), with first publication rights granted to the journal.

This is an open-access article distributed under the terms and conditions of the Creative Commons Attribution license (http://creativecommons.org/licenses/by/3.0/). 